\title{
Hydrodynamic Optimization for Design of a Submersible Axial-Flow Pump with a Swept Impeller
}

\author{
Youn-Sung Kim ${ }^{1,2}$, Man-Woong Heo ${ }^{3}$, Hyeon-Seok Shim ${ }^{2}$, Bong-Soo Lee ${ }^{4}$, Dong-Hwan Kim ${ }^{3}$ \\ and Kwang-Yong Kim ${ }^{2, * \mathbb{D}}$ \\ 1 FLUXYS Pump Company, Paju-si, Gyeonggi-do 10847, Korea; fluxys.pump@gmail.com \\ 2 Department of Mechanical Engineering, Inha University, Incheon 22212, Korea; shs_8341@inha.edu \\ 3 Coastal Development and Ocean Energy Research Center, Korea Institute of Ocean Science and Technology, \\ Busan 49111, Korea; mwheo@kiost.ac.kr (M.-W.H.); dhk@kiost.ac.kr (D.-H.K.) \\ 4 Korea Testing Certification, Gunpo-si, Gyeonggi-do 15809, Korea; bs7624@ktc.re.kr \\ * Correspondence: kykim@inha.ac.kr; Tel.: +82-32-860-7317
}

Received: 7 April 2020; Accepted: 9 June 2020; Published: 12 June 2020

check for updates

\begin{abstract}
Submersible pumps are now in high demand due to the sporadic occurrence of recent torrential rains. The current study was carried out to investigate the hydraulic characteristics of a submersible axial-flow pump with a swept impeller and to optimize the impeller and diffuser shapes of the pump to enhance the hydraulic performance. Three-dimensional Reynolds-averaged Navier-Stokes equations were solved with the shear stress transport turbulence model. The governing equations were discretized using the finite volume method, and unstructured tetrahedral and hexahedral meshes were used in the grid system. The optimal grid system was selected through a grid dependency test. A performance test for the submersible axial-flow pump was carried out experimentally, and the results of the numerical analysis were validated against the experimental results. The hydraulic efficiency and the total head were used as objective functions. For the first optimization, a multi-objective optimization was carried out to simultaneously improve the objective functions through a hybrid multi-objective evolutionary algorithm coupled with a response surface approximation by varying the swept angle and pitch angle of the blades of the rotating impeller. The second multi-objective optimization was performed using two design variables, i.e., the inlet angle and the length of the diffuser vanes, to simultaneously increase the objective functions. Clustered optimum designs in the Pareto optimal solutions yielded significant increases in the objective function values as compared with the reference design.
\end{abstract}

Keywords: submersible axial-flow pump; sweep angle; pitch angle; diffuser inlet and outlet angle; diffuser length

\section{Introduction}

Submersible axial-flow pumps have been used in Korea, since the early 1980s, for pumping out the water at drainage pumping stations. In recent years, due to the frequent occurrence of torrential rain, the demand for equipping a higher capacity pump system has been steadily and significantly increasing. Nowadays, the system has been used in various applications, such as drainage pumping stations and irrigation water supply facilities. In addition, recently, as continuity of water resource use has been emphasized, industries related to reuse water and desalination have been continuously growing.

In general, the submersible axial-flow pump is composed of a submersible motor, the inlet guide vanes (IGVs), a rotating impeller, and a diffuser. The design of axial-flow pumps considers the discharging flow rate and the head to determine the impeller rotational speed and the discharging diameter, and the best efficiency at the design point is taken into account to determine the power and the rotation speed of the motor. Submersible pumps used in drainage pumping stations operate for 
a relatively short period of time and have a long downtime. As a result, foreign substances such as soil and sludge are likely to be deposited inside the impeller or cling to the surface of the impeller blade. This can lead to a reduction of pump efficiency and clogging, which can be major causes of failures, such as confinement of an impeller or breaking of a motor. Therefore, recent studies have focused on improving the internal flow during the rotation and increasing the impeller surface flow rate to remove the foreign substances that adhere to the blade surface, by changing the shape of the impeller. This has required an understanding of the characteristics of submersible pumps by performing systematic analysis.

Kim et al. [1] analyzed the effects of the IGV angle on the hydraulic performance of a submersible axial-flow pump and confirmed that the incidence loss was reduced at all ranges of flow rates in accordance with an increase in the IGV angle and, particularly, that this angle imparted a substantial influence on increasing the efficiency in the high flow rate region. Pessoa and Prado [2] experimentally carried out an investigation on the two-phase flow characteristics inside a submersible pump. Shi et al. [3] suggested fundamental theories and methodologies for the design of a multiphased submersible pump. Moreover, Barrios and Prado [4] experimentally studied the detailed characteristics of the motion of bubbles and turbulence inside a submersible pump using visualization techniques.

Multistage electrical submersible pump performances with different viscosities of oil used as working fluid were numerically analyzed by Zhu et al. [5]. They found that the boosting pressure decreased as much as $30-40 \%$ by increasing the oil viscosity from 10 to $100 \mathrm{cp}$ and compared their numerical results with the corresponding experimental data under the water flow. Pineda et al. [6] investigated a problem that can result from a submersible pump in the oil and gas industry, viz., water/air two-phase flow, by a numerical analysis using the volume-of-fluid model. Additionally, Zhu et al. [7] performed experimental measurements to study the pressure surging phenomenon in a two-phase flow loop with a fourteen-stage radial type electrical submersible pump. Stel et al. [8] numerically identified the effects of the number of stages of submersible pumps on their performances. They also investigated the restriction caused by a reverse flow at the interface between the impeller and the diffuser. Chaudhari et al. [9] carried out a numerical analysis to predict the effects of the inlet, outlet, and the number of blades of the impeller on the head of a submersible mixed type pump. Zhou et al. [10] described the design methodology of a new type of diffuser, viz., a three-dimensional surface return diffuser for enhancing hydraulic performance of a submersible pump used in deep wells. Roclawski et al. [11] numerically and experimentally analyzed the performance characteristics of a modified submersible centrifugal pump stage which was designed by decreasing the diameter of the casing. Thus, numerous investigations to understand the flow characteristics of the submersible pumps have been carried out numerically and experimentally. In addition, high-performance designs of various pumps using optimization techniques have been of immense interest. Ling et al. [12] performed a parametric study to investigate the effects of the IGV configuration on the hydraulic performance of a multiphase submersible pump. They improved the hydraulic efficiency and the total head by using a design optimization technique. Song et al. [13] performed a multi-objective design optimization that simultaneously optimized the efficiency, vibration, and the sum of radial forces in a single-channel submersible pump. Si et al. [14] proposed a matrix method for the optimization of the results of the orthographic experiment using the parameters, outlet width, number of impeller blade, and inlet setting angle of the guide vane, to enhance the hydraulic performances of a multistage pump. Suh et al. [15] performed a multi-objective optimization to simultaneously increase the efficiency and the pressure of the second stage of a multiphase pump.

In order to prevent the problems of sludge deposition in advance, a couple of methods have been introduced [16-18]. Lee [16] suggested a sludge adhesion preventing device that was installed inside the pump and utilized the static electricity generated by the friction between the flow of water and the copper and carbon compound. Yeom [17] circumferentially installed jet nozzles on the casing of a submersible pump to inject fresh water and air to invoke the bubble jet effect that could improve the sludge removal. Joseph [18] developed a strainer equipped with plural angled slots, which considered 
the angle of impeller vanes, to throw any debris off from a fluid intake. Kliger [19] introduced an impeller with backswept blades in order to prevent the clogging of solids and reported that the backswept blades of the impeller helped to push the solids to the periphery while the impeller rotated. The swept impeller of the submersible pump evenly distributed the fluid flow from the hub to the shroud by improving the internal flow inside the blade passage. Kim et al. [20] performed a parametric study and analyzed the effects of geometric parameters of the swept impeller on the total efficiency and the head of a submersible axial-flow pump.

Although some studies on traditional submersible pumps have been carried out over the last decades, there is a lack of studies on the submersible axial-flow pumps with swept blades that enable the impeller to self-clean using the fluid flow evenly distributed in the blade passages. Understanding the hydrodynamic characteristics of the diffuser, as well as the rotating impeller, is crucial to concretely design a submersible axial-flow pump with a swept impeller.

In this study, three-dimensional Reynolds-averaged Navier-Stokes (RANS) analysis was performed to understand the internal flow characteristics of a submersible axial-flow pump with a swept impeller. A hydrodynamic optimization of the submersible pump was carried out in two stages through a hybrid multi-objective evolutionary algorithm (MOEA) coupled with a response surface approximation (RSA). Firstly, a multi-objective optimization was performed to simultaneously increase the objective functions, viz., the total efficiency and the head with the sweep and pitch angles as design variables. Secondly, the inlet angle and the length of the diffuser vanes of the pump installed with the optimum impeller were optimized to simultaneously improve the objective functions. The performance characteristics of the submersible axial-flow pump with the optimum impeller and diffuser vanes were also experimentally investigated through a performance test. The results of this study could contribute to the development of the serialization of the submersible pump with the swept impeller because there is no systematic design basis available for this pump type.

\section{Submersible Axial-Flow Pump Model}

Figure 1 illustrates the submersible axial-flow pump model of this work. The pump is composed of the suction and discharge columns, IGV, the rotating impeller, and the stationary diffuser domains. A motor shape was neglected in this numerical simulation. The numbers of IGVs and rotating impeller blades are commonly four. The impeller of the submersible axial-flow pump has a diameter of $550 \mathrm{~mm}$ and a tip clearance of $1 \mathrm{~mm}$, and the pump rotates at $700 \mathrm{rpm}$. The diffuser has six vanes and the diameters are 550 and $710 \mathrm{~mm}$ at the inlet and the outlet, respectively. The designed flow coefficient and the head coefficient are 0.047 and 0.031 , respectively. Detailed design specifications are given in Table 1.

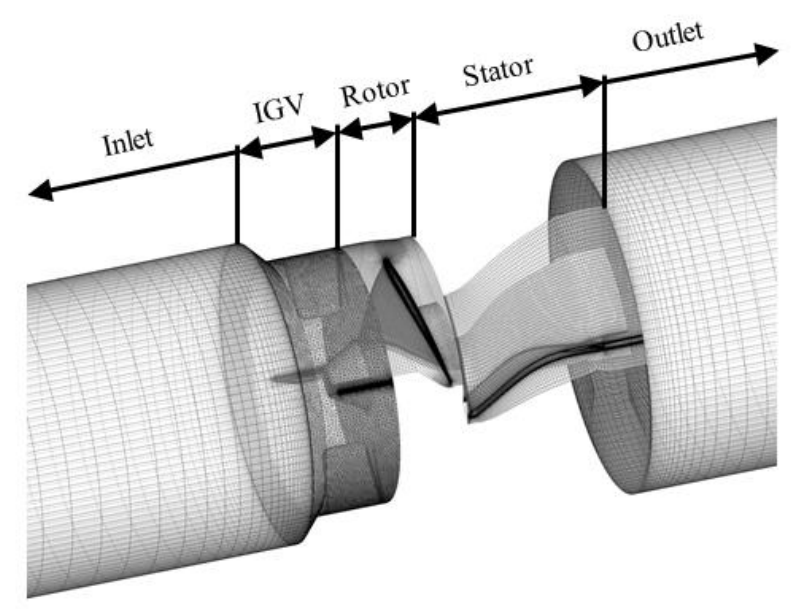

Figure 1. Computational domain and grid system. 
Table 1. Design specification of submersible axial-flow pump.

\begin{tabular}{cc}
\hline Parameter & Value \\
\hline Flow coefficient, $\Phi=Q / \omega D^{3}$ & 0.047 \\
Head coefficient, $\Psi=g H / \omega^{2} D^{2}$ & 0.031 \\
Rotational speed (rpm) & 700 \\
Impeller diameter (mm) & 550 \\
Tip clearance (mm) & 1 \\
Diffuser outlet diameter (mm) & 710 \\
Number of IGVs (EA) & 4 \\
Number of impeller blades (EA) & 4 \\
Number of diffuser vanes (EA) & 6 \\
\hline
\end{tabular}

\section{Numerical Methods}

To analyze the hydraulic characteristics of the submersible axial-flow pump with the changes in the configuration of diffuser vanes, an incompressible steady three-dimensional flow analysis was carried out using a commercial CFD code ANSYS CFX-16.0 ${ }^{\circledR}$ [21].

The computational domain for the flow analysis is presented in Figure 1. For the analysis of turbulence, the k- $\omega$ SST (shear stress transport) model [22] was used. The k- $\omega$ SST model combines the advantages of the $k-\omega$ and the $k-\varepsilon$ models by using the $k-\omega$ model in the region near the wall and the $k-\varepsilon$ model in the bulk-flow region.

The working fluid was single-phase water at $25^{\circ} \mathrm{C}$, and the total pressure and the mass flow rate were assigned at the inlet and outlet boundaries of the computation domain, respectively. The stage model was applied at the interface between the rotational and stationary domains, and solid surfaces were considered to be smooth and no-slip wall conditions were applied there.

The grid system was composed of tetrahedral meshes in the IGV domain and hexahedral meshes in the impeller, diffuser, suction, and discharge columns domains. The normalized distance of the first grid from the wall $(\mathrm{y}+)$ was maintained to be $<2$ to apply the low Reynolds number SST model. To find the optimal number of the grid system, a grid dependency test was carried out with the number of grids in a range of 1,500,000-12,000,000 in a previous study [20]. As the result, the optimal number of meshes for the computation were determined to be approximately $3,800,000$.

For convergence criteria, the root-mean-square (RMS) residual values for all governing equations were set to be less than $10^{-5}$. The variations in the performance parameters were maintained less than $0.5 \%$ during 100 time steps. The computations were performed using an Intel Core i7 CPU with $3.6 \mathrm{GHz}$ unit and MPICH, which subdivided a task into 8 for the parallel computation. The computation took approximately $12 \mathrm{~h}$ for a single analysis, and the time varied depending on the geometry and the convergence criteria.

The feasibility of the numerical analysis was verified by comparing the numerical analysis results with experimental data in the previous study [20], where a parametric study of the submersible pump with a conventional impeller was performed. The total efficiency and head values of the numerical analysis showed good agreements with the experimental data with relative errors of $1.6 \%$ and $0.7 \%$, respectively, at the design point. The neglect of the motor shape could have affected these errors.

\section{Experimental Apparatus}

The hydrodynamic performance characteristics of the pump prototype model were measured following the KS B 6320 standard [23] in the current study. A schematic diagram of the experimental setup for the performance test is shown in Figure 2. The submersible axial pump was vertically installed at the bottom of the pipe inside the water tank, and the pressure gauge, volume control valve, discharge pipe, and the flow meter were installed to measure the performance data. The length of the discharge pipe was 100 times the inlet diameter of the flow meter distancing from the valve, and the flow rate of the pump could be controlled by opening or closing the flow control valve. The water 
discharged from the pump flows back into the water tank, passed the distributing plate and circulates. The uncertainties of measurement (pressure and efficiency) in the experiment range were $\pm 0.306 \mathrm{~m}$ and $\pm 1 \%$, respectively (confidence level $95.45 \%$ and $\mathrm{k}=2$ ).

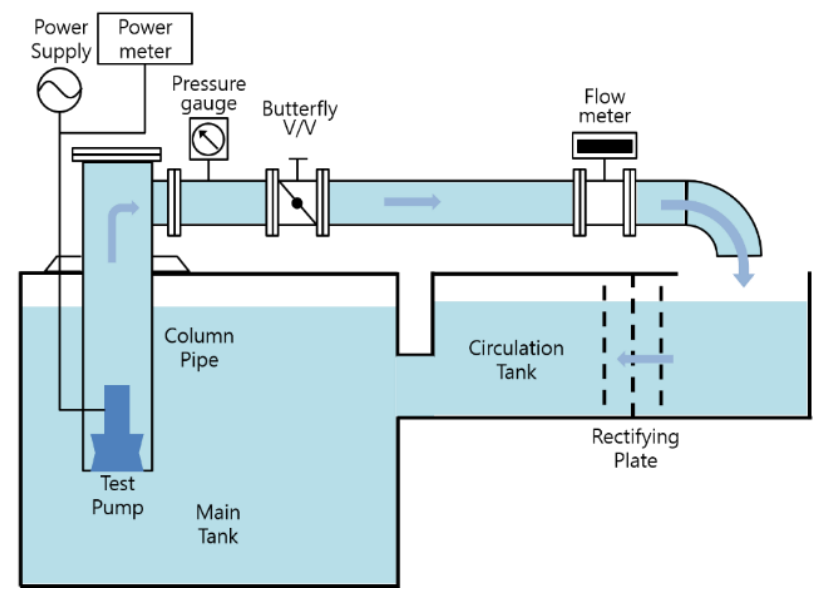

Figure 2. Schematic of experimental apparatus.

\section{Optimization Techniques}

Multi-objective optimizations were carried out to simultaneously enhance the total efficiency and the head of the submersible axial pump with the swept impeller. The definitions of the total efficiency and the head considered to be the objective functions are as follows:

$$
\begin{gathered}
\eta=\frac{\rho g Q H}{\left(\frac{2 \pi T R}{60}\right)} \\
H=\frac{P_{\text {out }}-P_{\text {in }}}{\rho g}
\end{gathered}
$$

where, $\rho, g, Q$, and $H$ mean the density of the working fluid, the acceleration by gravity, the flow rate, and the head, respectively; and $T, R$ and $P$ are the torque, rotational speed of the impeller, and the total pressure, respectively.

The multi-objective optimization was carried out in two stages for the impeller and the diffuser vanes, through the hybrid MOEA coupled with the RSA surrogate model. The aim of the first stage of the multi-objective optimization was to simultaneously improve the objective functions with the two design variables related to the swept angle and the pitch angle of the impeller blades. Then, the second stage of the multi-objective optimization based on the first optimization results was performed by the same method. The overall optimization procedures adopted in this work are described in the flow chart presented in Figure 3. First, design variables and objective functions were selected, and the ranges of the design variables were set up based on a parametric study.

The design space was filled with the sampling points obtained by the design of experiments (DOE) technique. Values of the objective functions were calculated at the sampling points, and surrogate models were constructed based on these calculated values. The Pareto optimal solutions (POSs) were finally obtained using the MOEA. POSs were the objective functions that could not be improved in value without degrading some of the others.

Latin hypercube sampling (LHS) [24] was used to select design (sampling) points in the design space as a DOE technique. LHS uses an $\mathrm{m} \times \mathrm{N}$ matrix where $\mathrm{m}$ and $\mathrm{N}$ are the number of levels of examination and the number of design variables, respectively. Each $\mathrm{N}$ column of the matrix containing $\mathrm{m}$ level rows is randomly paired to form a Latin hypercube. Accordingly, LHS generates a group of random sample points and ensures that it effectively fills the entire design space. Figure 4 shows the design points selected by the LHS for two design variables. In the present study, these design 
points were used as sampling points in space for the design variables of the swept impeller and the diffuser vanes.

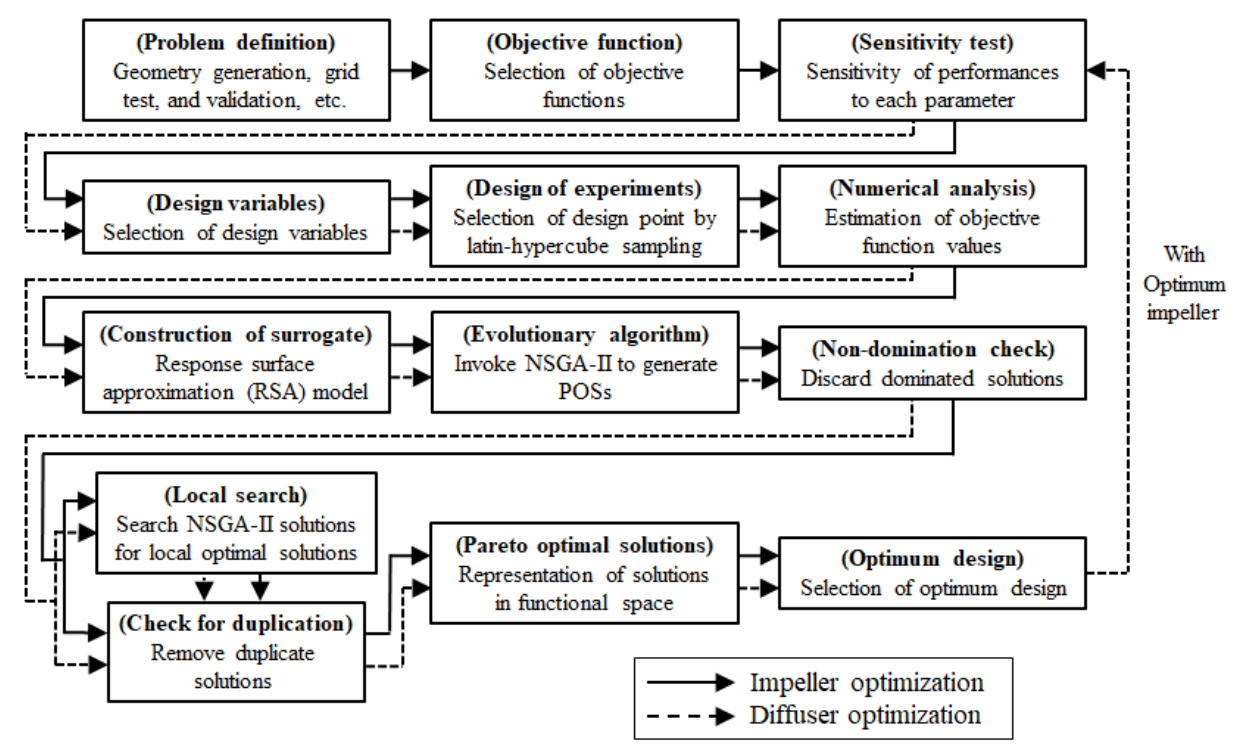

Figure 3. Overall optimization procedure.

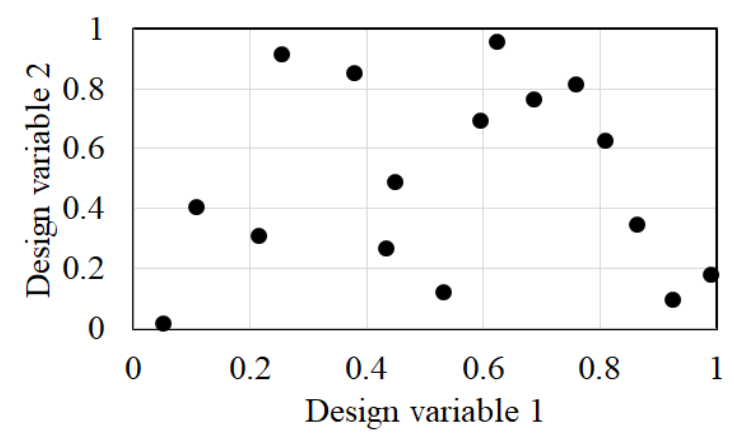

Figure 4. Design points of Latin hypercube sampling (LHS) for two design variables.

The RSA model was used to construct the surrogate model. The RSA model is a methodology that makes a polynomial function based on the discrete responses obtained by numerical calculations. A detailed explanation of the RSA model is presented in Myers and Montgomery [25]. The present work adopted a second-order polynomial for the response function, and the constructed response model for each objective function was formulated as follows:

$$
y(x)=\beta_{0}+\sum_{i=1}^{N} \beta_{i} x_{i}+\sum_{i=1}^{N} \beta_{i} x_{i}^{2}+\sum_{i<j}^{N} \beta_{i j} x_{i} x_{j}
$$

where $N, x$, and $\beta$ are the number of design variables, the vector of design variables, and the vector of unknown constant coefficients, respectively. The accuracy of this response function is evaluated using the $R^{2}$ adj value [25].

A hybrid MOEA was used to obtain POSs. In this algorithm, the approximate global POSs are initially obtained for each objective function using the real-coded fast and elitist NSGA-II which was suggested by Deb [26]. Here, the "real code" means that the crossover and the mutation are achieved in real space to get a response from NSGA-II. These initially guessed POSs obtained by NSGA-II are refined by searching local optimal solutions using the sequential quadratic programming (SQP) algorithm [27]. The SQP is a gradient-based optimization technique based on Newton's method. The local searching approach proceeds as follows: the first objective function is optimized, and the 
second objective function is regarded as an equality constraint. This local search is repeated for the second objective function regarding the first objective function as an equality constraint. The solutions obtained by these procedures are merged with the initial NSGA-II solutions, then, the dominated and duplicated solutions are removed to obtain the improved global POSs.

\section{Results and Discussion}

\subsection{Multi-Objective Optimization of the Impeller}

To simultaneously improve the total efficiency and the head of the submersible pump with the swept impeller, the hybrid MOEA coupled with the RSA surrogate model was employed in the multi-objective optimization procedure.

Figure 5 presents the definition of the sweep $(\theta)$ and pitch $\left(\beta_{r}\right)$ angles of the swept impeller. Changes in the angles $\left(\theta_{c}\right.$ and $\left.\beta_{c}\right)$ from the $\theta$ and $\beta_{r}$ of the reference shape were selected as two design variables based on the results of the previous study [20] which investigated the effects of the geometric parameters on the hydrodynamic performances of the submersible pump. Figure 5a shows the meridional plane of the swept impeller, and $\theta$ indicates the angle of inclination in the chord direction between the rotating axis and the line connecting the $25 \%$ chord of hub and the shroud of the blade.

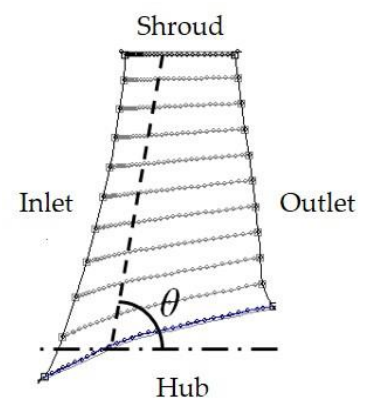

(a) sweep angle $(\theta)$

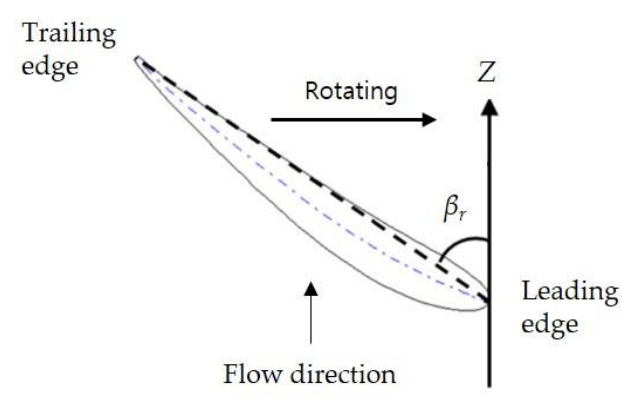

(b) blade pitch angle $\left(\beta_{\mathrm{r}}\right)$

Figure 5. Design variables of the swept impeller Kim et al. [20].

In the optimization procedure, the setup of the feasible design space formed by ranges of the design variables is important in predicting the optimum points. In this study, the design space was established based on results of a preliminary parametric study [20] and is presented in Table 2. Sixteen design points were generated within the design space using LHS. And the RANS analysis was carried out to evaluate the objective functions at the discrete design points.

Table 2. Ranges of the design variables of the swept impeller.

\begin{tabular}{ccc}
\hline Variables & $\boldsymbol{\theta}_{\boldsymbol{c}}$, Deg. & $\boldsymbol{\beta}_{\boldsymbol{c}}$, Deg. \\
\hline Lower bound & -8 & -4 \\
Upper bound & +6 & +4 \\
\hline
\end{tabular}

Regarding the results of the multi-objective optimization, the functional forms of the RSA model for the two objective functions can be expressed in terms of the design variables normalized between 0 and 1 as shown in the following equations:

$$
\begin{gathered}
\eta=75.6895-4.73059 \theta_{c}-0.513506 \beta_{c}+1.76209 \theta_{c} \beta_{c}-1.82734 \theta_{c}^{2}-3.25551 \beta_{c}{ }^{2} \\
H=4.93110+0.044064 \theta_{c}+1.05809 \beta_{c}+0.250351 \theta_{c} \beta_{c}+0.104467 \theta_{c}^{2}-0.600793 \beta_{c}{ }^{2}
\end{gathered}
$$


Figure 6 shows the global POSs, the reference design, the sixteen design points and the three representative clustered optimum designs (CODs). As objective function values for the total efficiency and the head are to be simultaneously maximized, a trade-off correlation was obviously shown between those values. A higher total efficiency was observed at a lower total head, and vice versa.

The values of the design variables and objective functions corresponding to the reference design and the three CODs extracted from the global POSs are listed in Table 3. Both the values of the two design variables of COD 2 are increased as compared with those of the reference design. Additionally, a decrease of $\theta_{c}$ and an increase of $\beta_{c}$ are confirmed as compared with those of the reference design and COD 1 and also with COD 3. Meanwhile, enhancement of both the objective functions is observed for all the CODs. The total efficiencies of CODs $1-3$ are relatively increased by $7.51 \%, 2.69 \%$, and $0.01 \%$, respectively, as compared with the reference design. In the case of COD 1 , the greatest increase in the total efficiency is observed. The relative increases of $0.19 \%, 5.97 \%$, and $9.25 \%$ in the total head of CODs 1-3 were shown, respectively, as compared with the reference design. It is noticeable that the combination effect between the two design variables of the swept impeller contributes to the enhancement of the objective function values. The objective function values predicted using the hybrid MOEA show less than 1\% discrepancies, except for the total efficiency (1.39\%) for COD 2 as compared with the results of the RANS analysis.

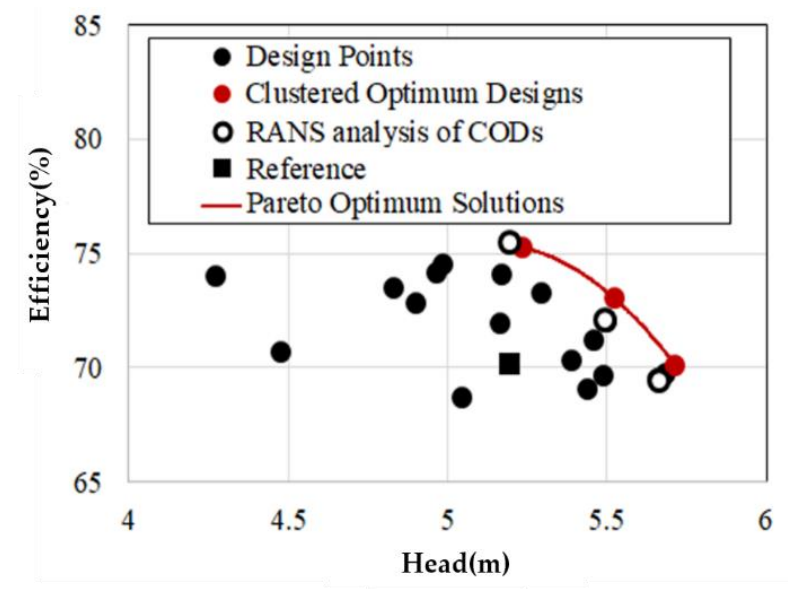

Figure 6. Results of Pareto optimal solutions (POSs) for the swept impeller.

Table 3. Results of the multi-objective optimization of the swept impeller.

\begin{tabular}{|c|c|c|c|c|c|}
\hline \multicolumn{2}{|c|}{ Description } & \multirow{2}{*}{$\begin{array}{c}\text { Reference Design } \\
-\end{array}$} & \multirow{3}{*}{$\begin{array}{c}\text { COD } 1 \\
-5.87 \\
+0.31\end{array}$} & \multirow{3}{*}{$\begin{array}{c}\text { COD } 2 \\
+3.39 \\
+3.51\end{array}$} & \multirow{3}{*}{$\begin{array}{c}\text { COD } 3 \\
-3.38 \\
+3.35 \\
\end{array}$} \\
\hline Desion variables & $\theta_{c}$ & & & & \\
\hline Design varıabies & $\beta_{\mathrm{c}}$ & - & & & \\
\hline \multirow{2}{*}{ Hybrid MOEA } & $\eta(\%)$ & - & 75.25 & 73.04 & 70.06 \\
\hline & $H(\mathrm{~m})$ & - & 5.24 & 5.52 & 5.72 \\
\hline \multirow{2}{*}{ RANS analysis } & $\eta(\%)$ & 70.15 & 75.42 & 72.04 & 70.16 \\
\hline & $H(\mathrm{~m})$ & 5.19 & 5.20 & 5.50 & 5.67 \\
\hline \multirow{2}{*}{ Discrepancy (\%) } & $\eta(\%)$ & - & 0.23 & 1.39 & 0.95 \\
\hline & $H(\mathrm{~m})$ & - & 0.74 & 0.44 & 0.85 \\
\hline \multirow{2}{*}{ Increment (\%) } & $\eta$ & - & 7.51 & 2.69 & 0.01 \\
\hline & $\dot{H}$ & - & 0.19 & 5.97 & 9.25 \\
\hline
\end{tabular}


Figure 7 shows the total pressure coefficient $\left(C_{T}\right)$ contours at $50 \%$ span of the swept impellers for the reference and $\operatorname{COD} 1 . C_{T}$ is defined as follows:

$$
C_{r}=\frac{P-P_{\text {in }}}{\frac{1}{2} \rho V^{2}}
$$

where $P$ is total pressure and $P_{\text {in }}$ is total pressure averaged at the inlet of the computational domain, and $V$ is the tip speed of the rotating impeller. In the reference design, the low total pressure region (red dashed circle) is widely distributed near the leading edge of the impeller. This total pressure distribution near the leading edge is improved in COD 1. The low total pressure in this region is improved as a consequence of the optimization and the improved total pressure presents the reason for the increased efficiency without having loss of the total head. In addition, it is observed that the total pressure distributions (red allow) near the pressure side of the swept impeller are also improved in COD 1.

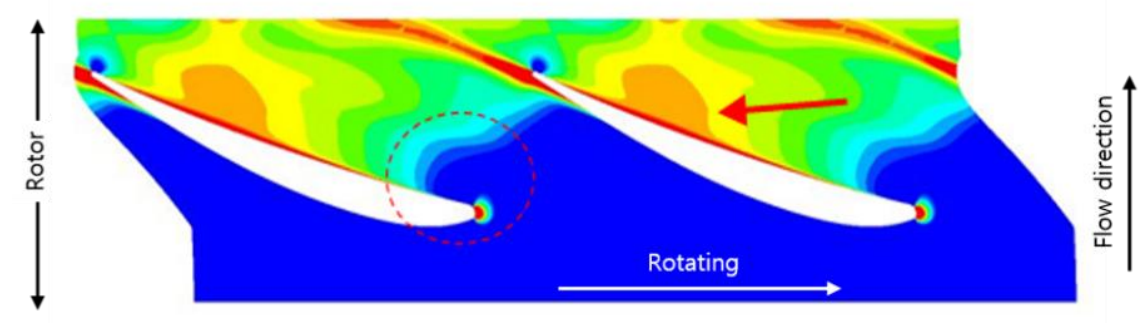

(a) Reference impeller

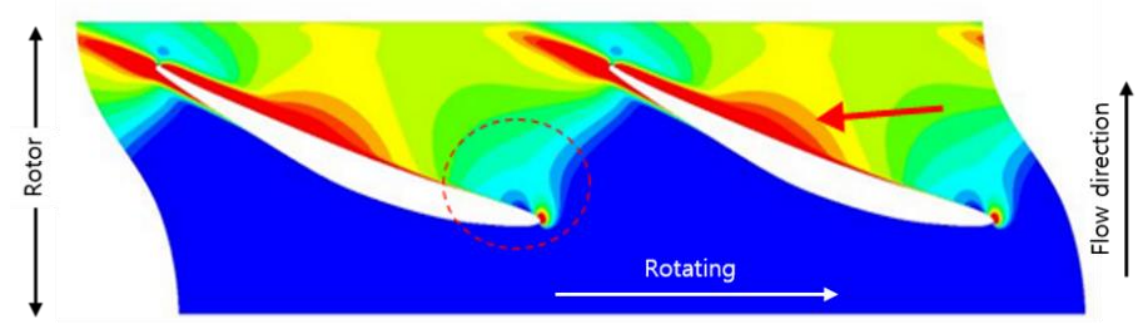

(b) COD 1

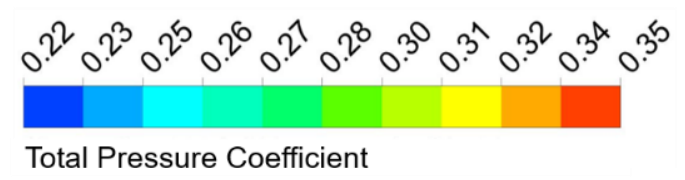

Figure 7. Total pressure coefficient contours at 50\% span of the impeller.

The relative total pressure coefficient $\left(C_{R T}\right)$ contours on the meridional plane for the reference and COD 1 impellers are presented in Figure 8. The $C_{R T}$ is calculated using the relative total pressure instead of the total pressure in Equation (6). In both cases, the relative total pressure is dependent on the radial position because the relative total pressure is associated with the relative velocity $\mathrm{W}$. For COD 1 , the relative total pressure values near $70 \%$ span and the leading edge are improved as compared with the reference model. The relative total pressure values of COD 1 are improved effectively by flow redistribution near the shroud where the high relative total pressures occur. These increased local relative total pressures enhance the total pressure rises by the rotor, resulting in the high head rise of COD 1 (Table 4).

Figure 9 shows the comparison of the incidence angles of the diffuser for the reference and COD 1 impellers. In both cases, high incidence angles of about $25^{\circ}$ occur near the diffuser shroud. The diffuser of the submersible pump with the COD 1 impeller has the incidence angles of less than $8^{\circ}$ below $75 \%$ span. However, the diffuser with the reference impeller has higher incidence angles than those with the COD 1, and shows a very high incidence angle of around $49^{\circ}$ near the hub. This incidence angle 
leads to generate a large vortex in the diffuser passage as shown in Figure 10a; Figure 10b shows that this vortex generation in the diffuser passages is suppressed by the design optimization of the impeller. It is noticeable that the improvement in the hydrodynamic performance of the submersible pump is caused by this suppression of the vortex generation in the diffuser passages.

Table 4. Rotor performances of optimum swept impellers.

\begin{tabular}{ccccc}
\hline \multirow{2}{*}{ Description } & \multicolumn{2}{c}{ RANS Analysis } & \multicolumn{2}{c}{ Increment (\%) } \\
\cline { 2 - 5 } & $\boldsymbol{\eta} \mathbf{( \% )}$ & $\boldsymbol{H} \mathbf{( m )}$ & $\boldsymbol{\eta} \mathbf{( \% )}$ & $\boldsymbol{H} \mathbf{( m )}$ \\
\hline Reference design & 85.83 & 6.36 & - & - \\
COD 1 & 86.56 & 6.41 & 0.84 & 0.87 \\
COD 2 & 86.01 & 6.50 & 0.21 & 2.25 \\
COD 3 & 83.46 & 6.78 & -2.76 & 6.72 \\
\hline
\end{tabular}

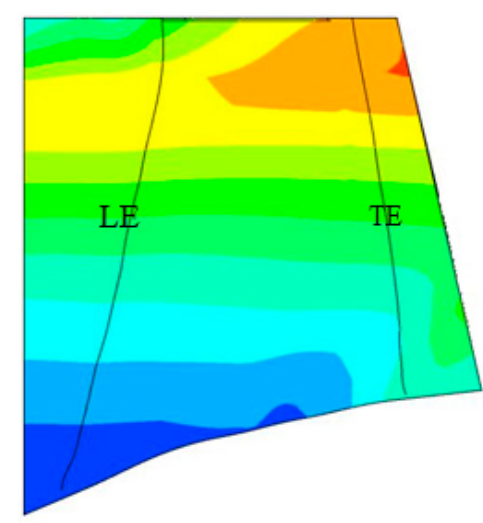

(a) Reference impeller

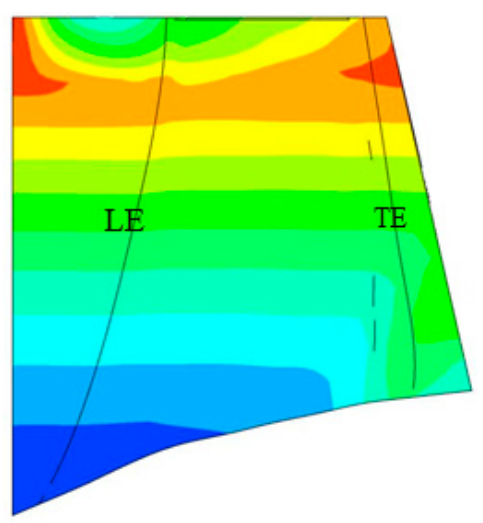

(b) COD 1

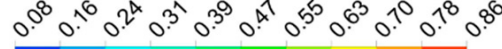

$$
\begin{aligned}
& \text { Relative Total Pressure Coefficient }
\end{aligned}
$$

Figure 8. Relative total pressure coefficient contours on the meridional plane of the impeller.

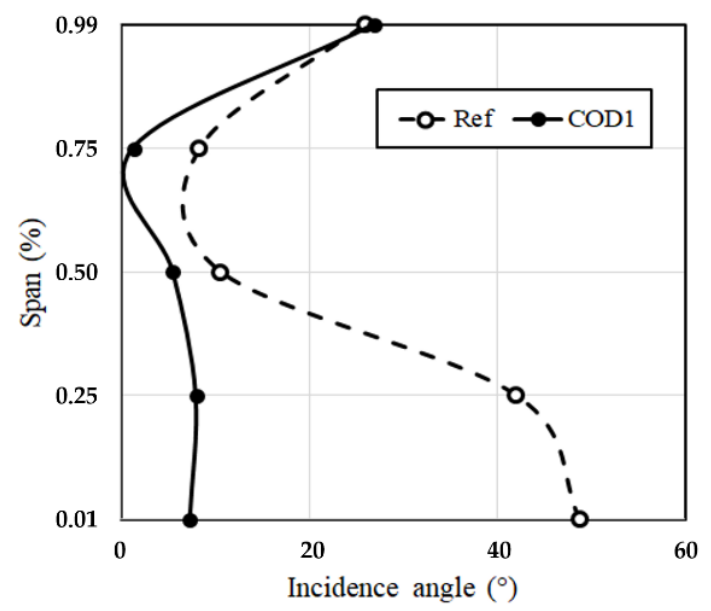

Figure 9. Comparison of incidence angles of the diffuser for the reference and COD 1 impellers. 


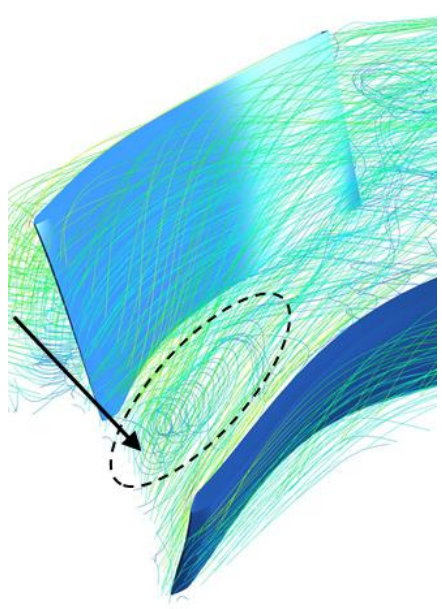

(a) Reference impeller

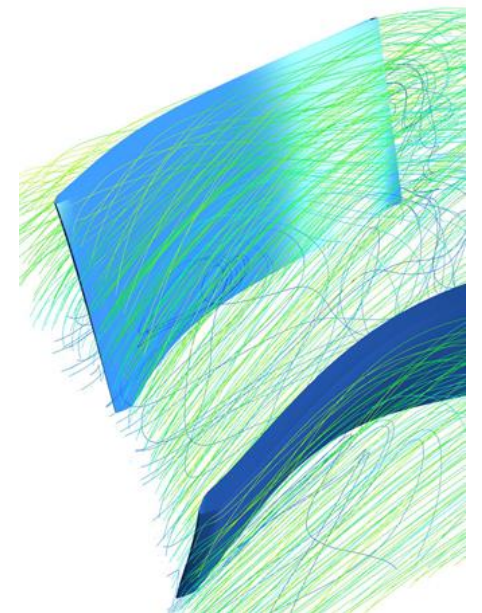

(b) COD 1

Figure 10. Streamlines in the passage of the diffuser.

\subsection{Multi-Objective Optimization of the Diffuser}

The inlet angle $\left(\beta_{s 1}\right)$ and the length $\left(L_{s}\right)$ of the diffuser of the submersible axial-flow pump are defined as shown in Figure 11. In the second-stage optimization, change in the angle $\left(\beta_{c 1}\right)$ from the inlet angle of the reference diffuser and change in the length $\left(L_{c}=L_{s} / L_{s r e f}\right)$ normalized with that of the reference diffuser are optimized to simultaneously maximize the total efficiency and the head of the submersible axial-flow pump with the COD 1 impeller. When the length of the diffuser is changed, the blade angle is not changed at the normalized position of the diffuser.

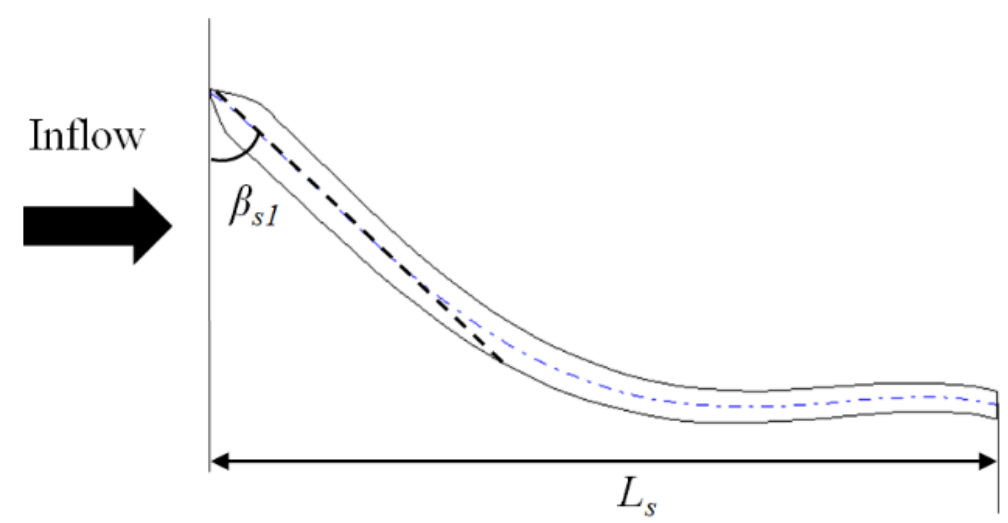

Figure 11. Inlet angle $\left(\beta_{s 1}\right)$ and length $\left(L_{s}\right)$ of the diffuser of the submersible axial-flow pump.

On the basis of the results of the parametric study from the previous study by Heo et al. [28], the range of design variables were determined, as shown in Table 5 . The sixteen design points were extracted within the range of the design variables through the LHS, as shown in Figure 4. Then, the objective function values were evaluated at the design points by solving the RANS equations.

Table 5. Ranges of the design variables for the diffuser.

\begin{tabular}{ccc}
\hline Variables & $\boldsymbol{\beta}_{\boldsymbol{c 1}}$, Deg. & $\boldsymbol{L}_{\boldsymbol{c}}\left(=L_{\boldsymbol{s}} / \boldsymbol{L}_{\text {sref }}\right)$ \\
\hline Lower bound & -9 & 0.9 \\
Upper bound & 20 & 1.3 \\
\hline
\end{tabular}


The following expressions in terms of the normalized design variables are the functional forms for the RSA model.

$$
\begin{gathered}
\eta=77.7222-1.21262 \beta_{c 1}+0.480914 L_{c}+2.49158 \beta_{c 1} L_{c}-0.339219 \beta_{c 1}^{2}-0.875502 L_{c}{ }^{2} \\
H=5.41609-0.348995 \beta_{c 1}-0.133129 L_{c}+0.216645 \beta_{c 1} L_{c}+0.141180 \beta_{c 1}^{2}+0.0628439 L_{c}{ }^{2}
\end{gathered}
$$

Figure 12 presents the global POSs, COD 1, the sixteen design points, and the three CODs, viz., COD 4, COD 5, and COD 6 . The values of design variables and objective functions with respect to these reference design, COD 1 and CODs 4-6, are listed in Table 6. COD 5 and COD 6 have decreased $\beta_{c 1} \mathrm{~s}$ as compared with the reference design, while the $\beta_{c 1}$ of COD 4 increased. CODs $4-6$ show larger values of $L_{s}$ than that of the reference design. CODs 4-6 show superior results to the COD 1 for both the objectives. In addition, CODs $4-6$ show improved total efficiencies as much as $1.30 \%, 0.77 \%$, and $1.52 \%$, and $2.88 \%, 3.08 \%$, and $4.42 \%$ increases in the total head, respectively. Consequently, the highest values of both the objective functions are observed from COD 6 which shows the smallest discrepancies between the predicted objective function values and the corresponding values of the RANS analysis among the CODs $4-6$. Therefore, COD 6 is selected as the final optimum design.

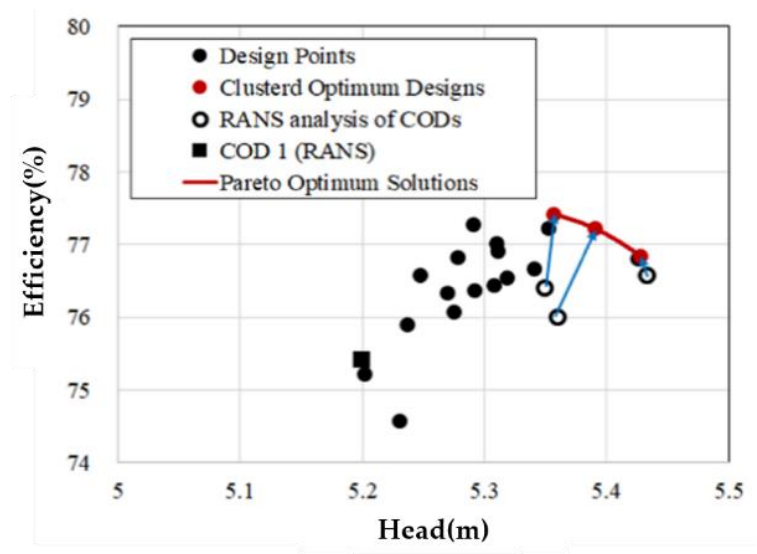

Figure 12. Results of POSs for the diffuser.

Table 6. Results of the multi-objective optimization of the diffuser.

\begin{tabular}{ccccccc}
\hline Description & & Reference Design & COD 1 & COD 4 & COD 5 & COD 6 \\
\hline \multirow{2}{*}{ Design variables } & $\beta_{c 1}$ & - & - & +3.00 & -2.96 & -8.70 \\
& $L_{c}$ & - & - & +1.14 & +1.14 & +1.13 \\
\hline \multirow{2}{*}{ Hybrid MOEA } & $\eta(\%)$ & - & 75.25 & 77.41 & 77.22 & 76.84 \\
& $H(\mathrm{~m})$ & - & 5.24 & 5.36 & 5.39 & 5.43 \\
\hline \multirow{2}{*}{ RANS analysis } & $\eta(\%)$ & 70.15 & 75.42 & 76.40 & 76.00 & 76.57 \\
& $H(\mathrm{~m})$ & 5.19 & 5.20 & 5.35 & 5.36 & 5.43 \\
\hline \multirow{2}{*}{ Discrepancy (\%) } & $\eta(\%)$ & - & - & 1.33 & 1.61 & 0.35 \\
& $H(\mathrm{~m})$ & - & - & 0.11 & 0.57 & 0.11 \\
\hline \multirow{2}{*}{ Increment (compared to } & $\eta$ & - & - & 1.30 & 0.77 & 1.52 \\
COD 1) (\%) & $H$ & - & - & 2.88 & 3.08 & 4.42 \\
\hline
\end{tabular}

Figure 13 presents the total pressure coefficient contours at 50\% span of the impeller and the diffuser for the reference design, COD 1, and COD 6. In the case of the reference design, the low total pressure region is widely spread in the passages of the diffuser. These regions are improved through the multi-objective optimization of the swept impeller, as shown in Figure 13b. It is noticeable that the flow downstream of the impeller affects the flow field of the diffuser, and the flow passage of the diffuser is also improved through the design optimization. COD 6 shows further improvement of the 
total pressure in the passage of the diffuser. However, the high total pressure region observed near the trailing edge of the diffuser is slightly diminished for COD 6.

The pressure coefficient contours at $50 \%$ span of the diffuser for the reference design, COD 1 and COD 6, are presented in Figure 14. The pressure coefficient is defined by using the static pressure instead of the total pressure in Equation (6). For the reference design, the pressure is increased along the pressure surface of the diffuser vanes and decreased from the $80 \%$ chord of the diffuser vanes. This decreasing pressure is improved for COD 1 as a result of optimization of the swept impeller. In addition, through the design optimization of the diffuser, the pressure distribution in the passages of the diffuser gradually increases from the leading edge to the trailing edge of the diffuser vane for COD 6.

Figure 15 presents the comparison between the velocity distributions of CODs 1 and 6 at $50 \%$ span of the diffuser vane. The velocity is normalized by the velocity averaged at the inlet of each diffuser. The velocity distributions of COD 6 show generally larger values than those of COD 1 . The velocities along the suction side of the diffuser vane of COD 6 decrease drastically from $40 \%$ normalized length, and have lower values than those of COD 1 from $65 \%$ normalized length. However, near the trailing edge of the diffuser, the normalized velocity of COD 6 becomes similar to that of COD 1 . This decrease in the velocity for COD 6 is due to the recovery of the static pressure. The sufficient recovery of the static pressure in COD 6 results in higher total pressure than that in COD 1. On the pressure side of COD 6 , the velocity remains nearly constant as the velocity averaged at the inlet.

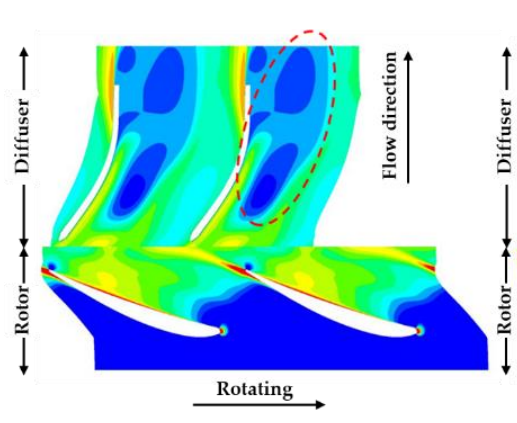

(a) Reference

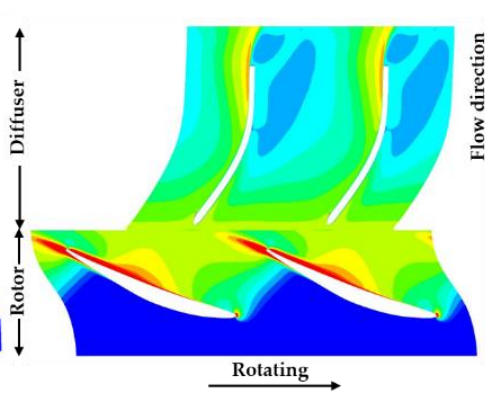

(b) COD1

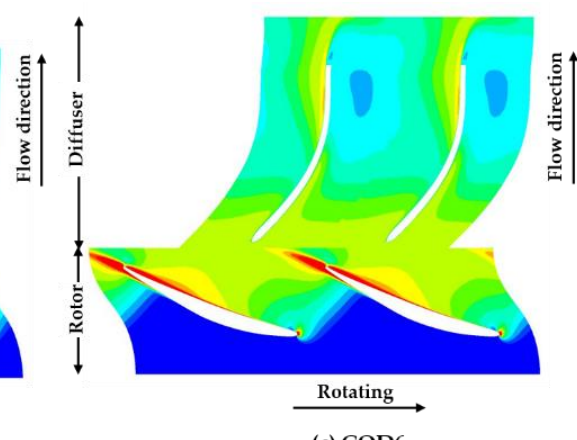

(c) COD6

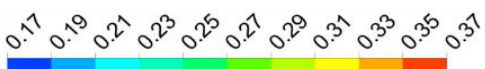

$$
\begin{aligned}
& \text { Normalized Total Pressure in Stn Frame }
\end{aligned}
$$

Figure 13. Total pressure coefficient contours at $50 \%$ span of the impeller and diffuser.

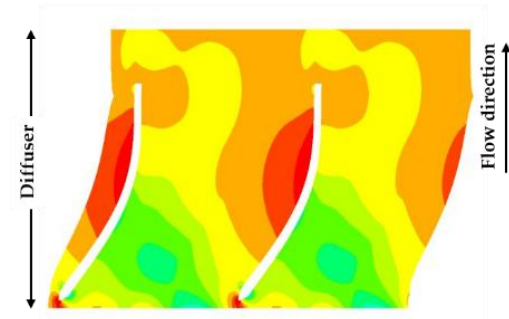

(a) Reference

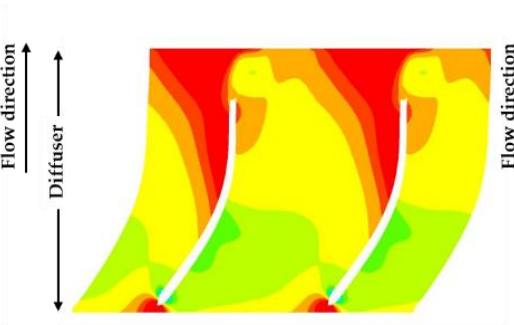

(b) COD 1

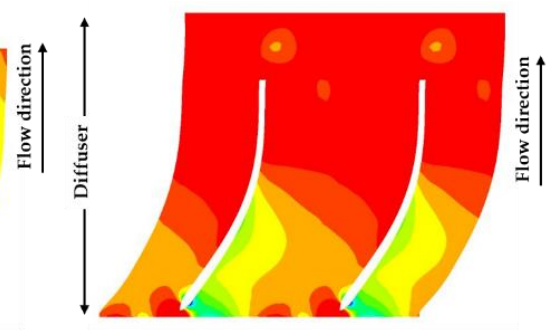

(c) $\operatorname{COD} 6$

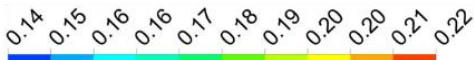

$$
\begin{aligned}
& \text { Normalized Pressure }
\end{aligned}
$$

Figure 14. Static pressure coefficient contours at 50\% span of the diffuser. 


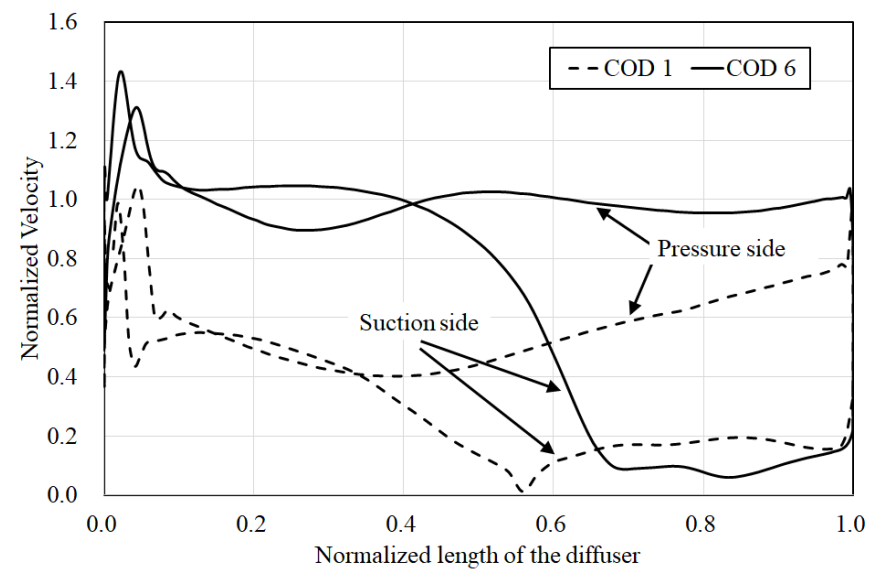

Figure 15. Velocity distributions at 50\% span of the diffuser vane.

In order to analyze the three-dimensional flow structure near the diffuser, the absolute helicity contours on the isosurface of the vorticity of $22 \mathrm{~s}^{-1}$ are compared among the reference, COD 1 , and COD 6, as shown in Figure 16. In the case of the reference diffuser, the vorticity increases along the streamwise direction, as shown in Figure 16a. Although CODs 1 and 6 have these vorticity regions at the inlet, they decrease as the flow proceeds. In particular, COD 6 has a relatively small vorticity region at the inlet of the diffuser. These phenomena can explain the total pressure contours, also shown in Figure 13.

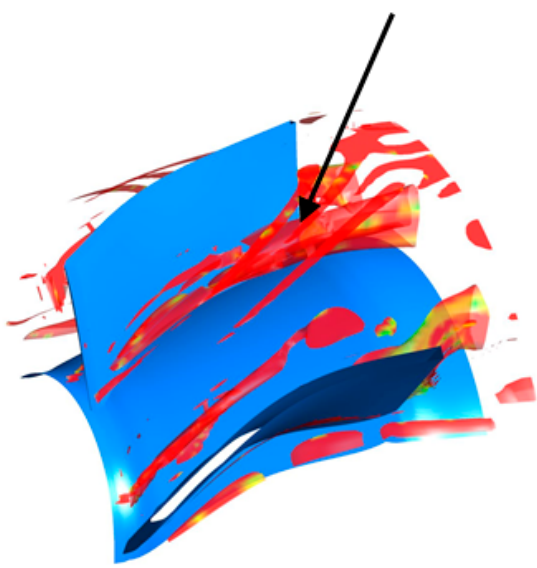

(a) Reference diffuser

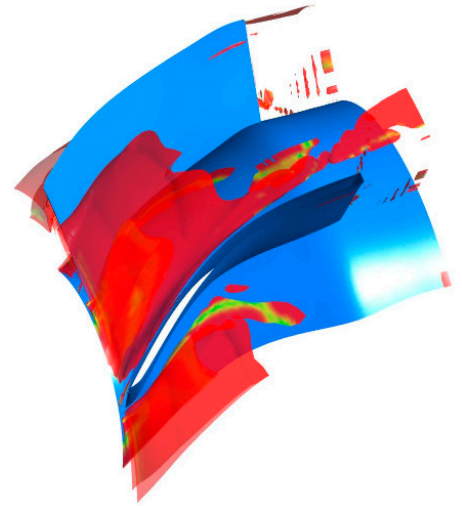

(b) COD 1

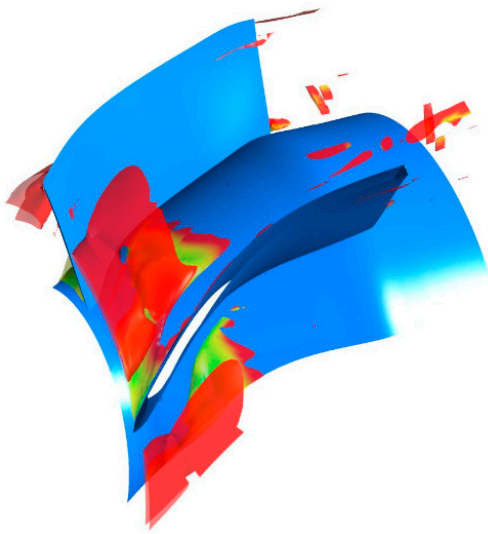

(c) $\operatorname{COD} 6$

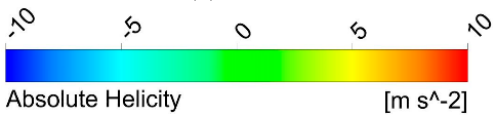

Figure 16. Absolute helicity contours on the vorticity region of $22 \mathrm{~s}^{-1}$ in the diffuser domain. 


\subsection{Performance Test}

The performance test for the submersible axial-flow pump with the swept impeller and the diffuser of COD 6 was performed to verify the validity of the present multi-objective optimization results. Figure 17 shows the experimental apparatus (left picture) schematized in Figure 2 and the optimum axial-flow pump (right picture) based on COD 6.

The results of the performance test and the comparison with the RANS analysis are presented in Figure 18 and Table 7. The RANS analysis predicted the higher efficiency and the lower head as much as $3.46 \%$ and $0.69 \mathrm{~m}$ as compared with the experiment, respectively, at the design point.
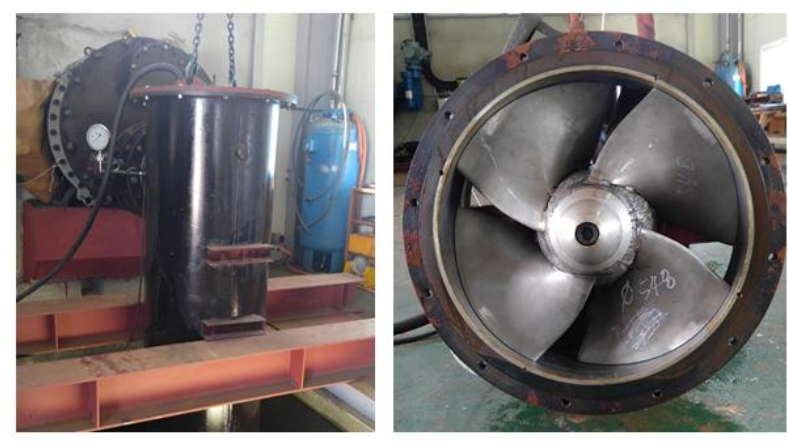

Figure 17. Experimental apparatus (left) and submersible axial-flow pump (right).

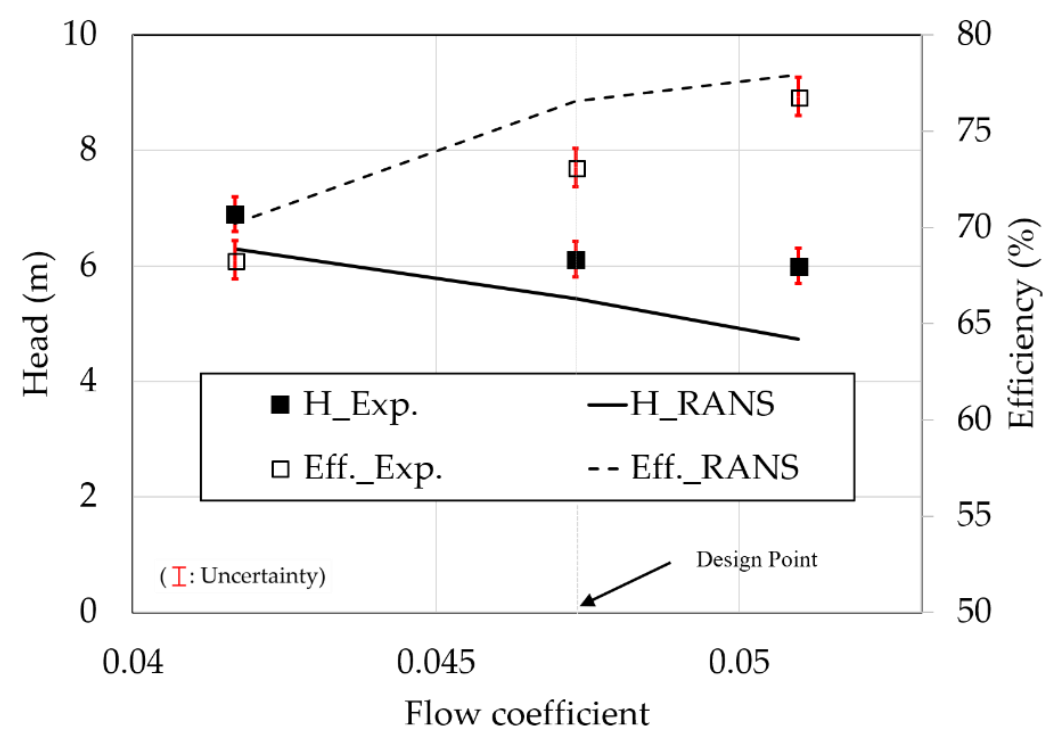

Figure 18. Comparison between the results of the experiment and RANS analysis for COD 6.

Table 7. Results of the performance test at the design point.

\begin{tabular}{cccc}
\hline Objective Functions & Exp. & RANS & Discrepancy \\
\hline$\eta(\%)$ & 73.11 & 76.57 & 3.46 \\
$H(\mathrm{~m})$ & 6.12 & 5.43 & 0.69 \\
\hline
\end{tabular}

\section{Conclusions}

A submersible axial-flow pump with a swept impeller was optimized to simultaneously improve the total efficiency and the head, which were considered as two objective functions.

Two stage optimizations were carried out sequentially through a hybrid MOEA coupled with a RSA model. The first multi-objective optimization was performed to simultaneously improve two 
objective functions with two design variables, i.e., the sweep and pitch angles of the swept impeller. The first optimization of the swept impeller achieved $7.51 \%$ and $0.19 \%$ increases in the total efficiency and the head, respectively, as compared with the reference design. Although the shape of the rotor was designed through the first design optimization, it was confirmed that the design of the rotor resulted in an improvement of the diffuser's performance rather than the performance of the rotor by changing the shape of the rotor. Consequently, the overall performance of the pump was improved. Then, the second multi-objective optimization was carried out to simultaneously improve the total efficiency and the head using the COD 1 impeller obtained from the first optimization. The inlet angle and the length of the diffuser vane were considered as two design variables. The final selected optimum pump design (COD 6) showed improvements of $9.03 \%$ and $4.61 \%$ in the total efficiency and the head, respectively, as compared with the reference design. In the second design optimization process, the design improved the static pressure recovery through the shape design of the diffuser. As a result, the total head and total efficiency increased in the optimum design.

The results of the RANS analysis for COD 6 with the optimum swept impeller and diffuser designs obtained from the present optimizations were validated against the performance test results performed in this work. The numerical results showed reasonable agreements with the experimental data throughout the whole range of the flow coefficient with relative discrepancies of $3.46 \%$ and $0.69 \mathrm{~m}$ for the total efficiency and the head, respectively, at the design point.

Author Contributions: Y.-S.K. presented the main idea of the swept impeller of submersible axial flow pump; Y.-S.K. and M.-W.H. contributed to the overall composition and writing of the manuscript; M.-W.H. and D.-H.K. analyzed the proposed swept impeller and performed numerical analysis; H.-S.S. and B.-S.L. performed experiments and analyzed the data; K.-Y.K. revised and finalized the manuscript. All authors have read and agreed to the published version of the manuscript.

Funding: The research was supported by a grant (no. S2765307) from the Korea Technology and Information Promotion Agency (TIPA) that is funded by the Ministry of SMEs and Startups (MSS) and a grant (17IFIP-B089065-04) from the Industrial Facilities \& Infrastructure Research Program (IFIP) funded by the Ministry of Land, Infrastructure and Transport of the Korean government. The authors gratefully acknowledge this support.

Conflicts of Interest: The authors declare there is no conflict of interest.

\section{Nomenclature}

\begin{tabular}{ll} 
CODs & Clustered optimum solutions \\
$H$ & Acceleration by gravity \\
$g$ & Total head \\
$L_{c}$ & Length normalized with $L_{S}$ of reference \\
$L_{s}$ & Length of diffuser vane \\
$P$ & Total pressure \\
$P_{i n}$ & Total pressure at the inlet \\
POSs & Pareto optimum solutions \\
$Q$ & Fluid flow rate \\
$R$ & Rotational speed of impeller \\
$T$ & Torque \\
$\beta_{c}$ & Angle changed from $\beta_{r}$ of reference \\
$\beta_{c 1}$ & Angle changed from $\beta_{s 1}$ of reference \\
$\beta_{s 1}$ & Inlet angle of diffuser vane \\
$\beta_{r}$ & Pitch angle of impeller \\
$\eta$ & Total efficiency \\
$\theta$ & Sweep angle of impeller \\
$\theta_{c}$ & Angle changed from $\theta$ of reference \\
$\rho$ & Density \\
$\varphi$ & Flow coefficient \\
$\psi$ & Head coefficient \\
$\mathrm{k}$ & Coverage factor \\
$V$ & Rotating tip speed of the rotor \\
& \\
\hline &
\end{tabular}




\section{References}

1. Kim, Y.S.; Shim, H.S.; Kim, K.Y. Hydraulic performance characteristics of a submersible axial-flow pump with different angles of inlet guide vane. KSFM J. Fluid Mach. 2018, 21, 34-40. [CrossRef]

2. Pessoa, R.; Prado, M. Experimental investigation of two-phase flow performance of electrical submersible pump stages. In Proceedings of the SPE Annual Technical Conference and Exhibition, New Orleans, LA, USA, 30 September-3 October 2001; SPE 71552.

3. WShi, D.; Lu, W.G.; Wang, H.L.; Li, Q.F. Research on the theory and design methods of the new type submersible pump for deep well. In Proceedings of the ASME 2009 Fluids Engineering Division Summer Meeting, Vail, CO, USA, 2-6 August 2009; FEDSM200-FEDSM78099.

4. Barrios, L.; Prado, M.G. Experimental visualization of two-phase flow inside and electrical submersible pump stage. J. Energy Resour. 2011, 133, 042901. [CrossRef]

5. Zhu, J.; Banjar, H.; Xia, Z.; Zhang, H.Q. CFD simulation and experimental study of oil viscosity effect on multi-stage electrical submersible pump (ESP) performance. J. Pet. Sci. Eng. 2016, 146, 735-745. [CrossRef]

6. Pineda, H.; Biazussi, J.; Lopez, F.; Oliveira, B.; Carvalho, R.D.M.; Bannwart, A.C.; Ratkovich, N. Phase distribution analysis in an electrical submersible pump (ESP) inlet handling water-air two-phase flow using computational fluid dynamics (CFD). J. Pet. Sci. Eng. 2016, 139, 49-61. [CrossRef]

7. Zhu, J.; Guo, X.; Liang, F.; Zhang, H.Q. Experimental study and mechanistic modeling of pressure surging in electrical submersible pump. J. Nat. Gas Sci. Eng. 2017, 45, 625-636. [CrossRef]

8. Stel, H.; Sirino, T.; Ponce, F.J.; Chiva, S.; Morales, R.E.M. Numerical investigation of the flow in a multistage electric submersible pump. J. Pet. Sci. Eng. 2015, 136, 41-54. [CrossRef]

9. Chaudhari, S.C.; Yadav, C.O.; Damor, A.B. A comparative study of mix flow pump impeller CFD analysis and experimental data of submersible pump. Int. J. Res. Eng. Technol. 2013, 1, 57-64.

10. Zhou, L.; Shi, W.D.; Hu, W.G.L.B.; Wu, S.Q. Numerical investigations and performance experiments of a deep-well centrifugal pump with different diffusers. J. Fluids Eng. 2012, 134, 071102. [CrossRef]

11. Roclawski, H.; Weiten, A.; Hellmann, D.H. Numerical investigation and optimization of a stator for a radial submersible pump stage with minimum stage diameter. In Proceedings of the ASME 2006 Fluids Engineering Division Summer Meeting, Miami, FL, USA, 17-20 July 2006; FEDSM2006-98181.

12. Ling, Z.; Weidong, S.; Weigang, L.; Rongjun, X.; Chuan, W. Orthogonal test and optimization design of submersible pump guide vanes. J. Drain. Irrig. Mach. Eng. 2011, 29, 312-315.

13. Song, W.G.; Ma, S.B.; Choi, Y.S.; Lee, K.Y.; Kim, Y.S.; Kim, K.Y.; Kim, J.H. Multi-objective optimization for designing a high-efficiency and low-fluid-induced-vibration single-channel pump. KSFM J. Fluid Mach. 2018, 21, 30-38. [CrossRef]

14. Si, Q.R.; Yuan, S.Q.; Yuan, J.P.; Wang, C.; Lu, W.G. Multi objective optimization of low-specific-speed multistage pumps by using matrix analysis and CFD method. J. Appl. Math. 2013. [CrossRef]

15. Suh, J.W.; Kim, J.W.; Choi, Y.S.; Kim, J.H.; Joo, W.G.; Lee, K.Y. Multi-objective optimization of the hydrodynamic performance of the second stage of a multi-phase pump. Energies 2017, 10, 1334. [CrossRef]

16. Lee, U.S. Pump with Device for Preventing Sludge Adhesion. Korea Patent KR101372831B1, 15 July 2013.

17. Yeom, K.J. A Sludge Removal Apparatus of Pump Using a Bubble Jet. Korea Patent KR101670077B1, 15 April 2016.

18. Joseph, W.L. Self-Clearing Strainer for Fluid Intake. U.S. Patent 7501058B1, 12 May 2008.

19. Kliger, I. Wastewater Pump clog resistance cannot be determined by throughlet size. In Flygt Throughlet White Paper; Xylem, Inc.: Rye Brook, NY, USA, 2012; FWP001-1438; 4p.

20. Kim, Y.S.; Kim, K.Y.; Heo, M.W. Effects of geometric parameters on hydraulic performance of a submersible axial flow pump with swept impeller. KSFM J. Fluid Mach. 2019, 22, 19-27. [CrossRef]

21. ANSYS CFX 17.0. ANSYS CFX Tutorials; ANSYS Inc.: Pittsburgh, PA, USA, 2016.

22. Menter, F.R. Two-Equation Eddy-Viscosity Turbulence Model for Engineering Applications. AIAA J. 1994, 32, 1598-1606. [CrossRef]

23. KS B 6320. Submersible Motor Pumps for Deep Well; Korean Standards Association: Seoul, Korea, 2015.

24. Sacks, J.; Welch, W.J.; Mitchell, T.J.; Wynn, H.P. Design and analysis of computer experiments. Stat. Sci. 1989, 4, 409-435. [CrossRef]

25. Myers, R.H.; Montgomery, D.C. Response Surface Methodology: Process and Product Optimization Using Designed Experiments; John Wiley \& Sons Inc: New York, NY, USA, 1995. 
26. Deb, K. Multi-Objective Optimization Using Evolutionary Algorithms, 1st ed.; John Wiley \& Sons Inc.: Chichester, UK, 2001.

27. MATLAB. The Language of Technical Computing; Release 14; Math Work Inc.: Natick, MA, USA, 2004.

28. FLUXYS Pump Company. Indigenous Development of a Submersible Axial Flow Pump (45kW Class) With a Self-Cleaning Backswept Impeller; Korea Technology and Information Promotion Agency: Daejeon, Korea, 2018; No. S2522342. article distributed under the terms and conditions of the Creative Commons Attribution (CC BY) license (http://creativecommons.org/licenses/by/4.0/). 